\title{
Outcomes of a home-based pulmonary maintenance program for individuals with COPD: A pilot study
}

Marie Cooke RN; PhD

Deputy Head of School of Nursing \& Midwifery, Nathan,

Research Centre for Clinical \& Community Practice Innovation,

Griffith University,

Nathan, QLD, 4111

Tel: 0737357985

Fax: 0737355431

Email: m.cooke@griffith.edu.au

Wendy Moyle RN; PhD

Deputy Director of Research Centre for Clinical \& Community Practice Innovation, Research Centre for Clinical \& Community Practice Innovation,

Griffith University,

Nathan, QLD, 4111

Tel: 0737355526

Fax: 0737355431

Email: w.moyle@griffith.edu.au

\section{Susan Griffiths BA}

Senior Research Assistant,

Research Centre for Clinical \& Community Practice Innovation,

Gold Coast Campus

Griffith University,

QLD, 4222

Tel: 0755528937

Fax: 0755529144

Email: s.griffiths@griffith.edu.au

\section{Louise Shields (RN)}

Clinical Nurse,

Brisbane South Respiratory Service,

Corinda Community Health,

Division of Community and Primary Health Services,

Corinda QLD 4075

Tel: 0737102222

Fax: 0737102200

Email:Louise_Shields@health.qld.gov.au 


\section{Abstract}

This preliminary pilot study explores sustained benefits of pulmonary rehabilitation (PR) in people with chronic obstructive pulmonary disease (COPD) attending a 12 month home-based pulmonary maintenance program. The incidence of COPD is high and ageing populations will see this continue and possibly increase. PR programs are effective, however, benefits may dissipate if the program is not continued. The maintenance program involved: strength retraining exercises; collaborative goal setting; regular telephone calls; and home visits. Around half of the 29 participants remained in contact with the program for 12 months and 21 completed final or 6 month assessment. Most participants maintained: respiratory functioning; quality of life; and self-efficacy, with some showing improvements. Outcomes provide knowledge for improving patient care through a home-based strategy to maintain benefits of PR programs. Results suggest that in light of likely decline in benefits six twelve months after PR, the maintenance program contributed to sustained benefits for COPD individuals.

Keywords: nursing, pulmonary rehabilitation, COPD, quality of life, self-efficacy, respiratory function

\section{INTRODUCTION}

Chronic obstructive pulmonary disease (COPD) is the term used to incorporate a number of disorders including chronic bronchitis, emphysema and chronic asthma. It is widely accepted that COPD has a significant impact on individuals and their families, health care systems and society in general. In 2000, the World Health 
Organization estimated that 2.74 millon deaths were caused worldwide as a result of COPD (WHO 2000). Specifically, in Australia, 5,597 (8.3\% of all deaths) people died from COPD in 2002 (AIHW 2004), whilst in the United States (U.S.) approximately 119,000 adults aged 25 and over died from COPD in 2000 (National Center for Health Statistics, U.S. Department of Health and Human Services 2000). In light of these figures, it is not surprising that the economic burden that COPD places on countries is great. McKenzie et al. (2003) claim that treatment and maintenance conservatively costs Australia around $\$ 818$ - 898 million annually. The estimated total cost of managing COPD in the U.S., in 2002, was \$32.1 billion - \$18 billion of which were direct costs (National Heart, Lung and Blood Institute, U.S. Department of Health and Human Services 2002), whilst in the European Union, COPD is thought to account for 38.6 billion Euros anually (European Respiratory Society 2003). Tobacco smoking is recognised as the major risk factor for the development of COPD (Global Initiative for Chronic Obstructive Lung Disease 2007). However, in some countries, evidence suggests that air pollution directly resulting from the burning of wood and biomass fuels is also a significant risk factor for COPD development (Global Initiative for Chronic Obstructive Lung Disease 2007). The overall incidence of COPD is expected to increase in line with the aging population and exposure to COPD risk factors.

Mortality from COPD comes after a number of years of morbidity. The breathlessness created by COPD impacts on sleep, work, social activities and can result in a loss of self-esteem and independence. COPD is incurable so the goal of health care delivery is to provide support to individuals so as "to improve quality of life, increase exercise capacity and reduce morbidity and mortality” (McKenzie et al. 2003, p.7). In light of this set of goals, a joint project conducted by the Thoracic Society of Australia and 
New Zealand and the Australian Lung Foundation developed evidence-based care guidelines that: "Confirm diagnosis, Optimise function, Prevent deterioration, Develop a self-management plan and manage eXacerbations” (COPDX Plan) (McKenzie et al. 2003, p.7).

\section{BACKGROUND}

\section{Pulmonary Rehabilitation Programs}

In recent years, health care organisations have utilised the guidelines and commenced both in-patient and home-based pulmonary rehabilitation (PR) programs. There is considerable evidence that rehabilitation programs for COPD patients show clinically and statistically significant improvements: benefits include reducing dyspnoea (Lacasse et al. 2001); anxiety (Celli 1995, Covey et al. 2001); depression (Covey et al. 2001); improving exercise capacity (Lacasse et al. 2001); and quality of life (Wijkstra et al. 1994). There is also some evidence that rehabilitation programs may reduce hospitalizations (Griffiths et al. 2000). Lacasse et al. (2001) recommend, following a systematic review, that no further randomized controlled trials are needed to compare these programs with conventional COPD care. In a meta-analysis of 19 studies the average rehabilitation program was reported to be 11 weeks (ranging from three weeks to six months) in duration and predominantly administered in hospitalbased locations for both in- and out-patients (Oh \& Seo 2006), with some PR programs being delivered in community settings (Man et al. 2004). Most rehabilitation programs, in order to help restore patient independence and functioning, include patient education, exercise training, and psychosocial support and findings from this vast literature indicate that the risks of integrated programs are minimal. The benefits of rehabilitation programs however have been shown to dissipate after 6 
- 12 months (Foglio, Ambrosino \& Agati 2007) and, unfortunately, relatively little is known about strategies to maintain the benefits of such programs (Oh \& Seo 2006, Romagnoli et al. 2006, Lacasse et al. 2001).

\section{Maintenance Exercise Programs}

The unequivocal benefits of pulmonary rehabilitation and the general consensus that these benefits decline after six months have brought increased attention to the efficacy of pulmonary maintenance programs. Within the reviewed literature, five studies were found to have investigated the effects of different types of maintenance exercise programs for individuals with COPD. These maintenance programs typically involved administering the same exercises and training as required in a rehabilitation program but at more regular intervals. These studies were mostly international research and were conducted between two - 12 years ago, therefore highlighting the need for current research into the area. The oldest study reported that, at 18 months, individuals receiving no treatment maintenance had significantly deteriorated in their exercise tolerance when compared to those receiving monthly and weekly maintenance visits by a clinical practitioner (Wijkstra et al. 1996). In Grosbois et al.'s (1999) research it was reported that, at 18 months, individuals who undertook either supervised or unsupervised maintenance exercise had made improvements in their maximal work rate, whereas those individuals who had no maintenance had no improvements. Puente-Maestu et al. (2003) compared a supervised and self-monitored eight-week leg exercise training program and reported that, at 13 months, there were small improvements in all individuals' tolerance of an intense constant work rate task and health-related quality of life compared to the unsupervised exercise program. A more recent study (Romagnoli et al. 2006) found that a more frequently repeated maintenance program (at six and 12 months compared with just at 12 months) led to 
additional long-term physiological gains for individuals. Finally, an Australian study investigating the effect of a 40 week community-based maintenance exercise program reported that people with moderate to severe COPD maintained PR benefits and that attrition in the program was mostly due to medical problems (Cockram, Cecins \& Jenkins 2006).

\section{METHODS}

Aim

The aim of this pilot study was to gain preliminary data, to assist in the design of a larger study, on the effectiveness of a 12 month home-based pulmonary maintenance program (PM) on COPD individuals' levels of: self-efficacy; functional exercise capacity; respiratory functioning; and, quality of life.

\section{Design}

The study used a one-group longitudinal pre-test post-test design. The University and Institution's human research ethics committees gave ethics approval. The study was two years in duration, with staggered recruitment of groups of $6-10$ participants from July 2005 - July 2006 and follow-up in the subsequent year.

\section{Sample and Setting}

To be included in the study, participants had to meet the following eligibility criteria:

- a diagnosis of COPD

- a referal to the Community Respiratory Service of the site hospital

- completion of an eight-week pulmonary rehabilitation program between June 2005 and June 2006

- ability to read and write English sufficiently to complete the outcome measures.

After completing a pulmonary rehabilitation program at either of the two large tertiary hospitals, individuals referred to the Community Respiratory Service were contacted 
by telephone by the Community Respiratory Nurse Educator regarding their participation in the home-based maintance program. Those individuals seeking to participate and who had made an appointment for the initial assessment visit were mailed a written information sheet outlining the study. At the initial maintenance program visit, if eligible for inclusion, individuals were: reminded about the study; referred to the material previously sent; and then invited to participate in the study. Consenting individuals signed an informed consent sheet.

\section{Intervention}

The 12 month pulmonary maintenance program was commenced 4 weeks following the completion of PR program and consisted of a range of strategies to sustain optimum respiratory function for those with COPD. The strategies included:

- a generic exercise program that included: a warm-up; strength exercises; balance exercises; and stretches. The program was progressive in intensity, spanning a 12 month period

- collaborative goal setting (between client and Community Respiratory Nurse Educator), in relation to the maintenance program generally, at the initial home visit and revision at subsequent six and 12 month visits at the site hospital

- weekly telephone calls from the Community Respiratory Nurse Educator for the first month and at two, five, eight and 10 months to assess and monitor progress and provide advice

- a home visit by the Physiotherapist at months one and three to assess and review progress in the home enviornment. 


\section{Data Collection}

A range of pre, during and post-test data was collected by the Community Respiratory Nurse Educator and Physiotherapist at: baseline; six months (mid program) and 12 months (end of program). Final follow-up of participants was at 13 months after the completion of the PR program. This duration was considered likely to detect a possible dissipation of benefits gained from the PR program in line with Foglio, Ambrosino \& Agati (2007) who report attenuation between six and 12 months. All the following measures were used at each time point: a six-minute walk test; spirometry (although spirometry was not used as an outcome measure); the Pulmonary Maintenance Program Assessment which included the Medical Research Council (MRC) Dyspnoea Scale and the Patient Specific Functional Scale (PSFS); Short Form (SF) - 36 Health Survey; and the St-George’s Respiratory Questionnaire (SGRQ). The COPD Self-Efficacy Scale was used only at pre and post-intervention.

\section{Self-efficacy}

The COPD Self-Efficacy Scale (Wigal, Creer \& Kotses 1991) measures the level of confidence regarding an individuals' ability to manage or avoid breathing difficulties. The scale consists of 34 items, comprised of five subscales that measure: negative affect; intense emotional arousal; physical exertion; weather/environment; and behavioural risk factors. Individuals repond to each item on a five-point Likert scale. This scale has been used consistantly in clinical settings and has high internal consistency, with a Cronbach's alpha of 0.92 and 0.94 (Wigal, Creer \& Kotses 1991; Kara \& Asti 2004).

\section{Functional exercise capacity}


Functional exercise capacity was measured by a six minute walk test. This test is a simple, objective evaluation of functional capacity (American Thoracic Society 2002) and is commonly used as an outcome measure in clinical practice for clients with severe heart or lung disease (American Thoracic Society 2002; Sciurba et al. 2003).

\section{$\underline{\text { Respiratory function }}$}

Respiratory function was measured firstly by spirometry. Spirometry, described as “the gold standard for diagnosing, assessing and monitoring COPD” (McKenzie et al. 2003, p.11), is used to measure the airflow limitations of COPD (Bestall et al. 1999; McKenzie et al. 2003), with the forced expiratory flow in one second (FEV $\left.{ }_{1}\right)$ the measure most closely associated with prognosis (McKenzie et al. 2003). Secondly, the Pulmonary Maintenance Program Assessment which included the Medical Research Council (MRC) Dyspnoea scale and the Patient Specific Functional Scale (PSFS) was also used to measure respiratory function. The current disease symptom section used the MRC Dyspnoea scale: a five-item questionnaire where participants indicate their level of disability. This scale has been used extensively since 1959 as the standard for assessing the functional status of people with COPD and is regarded as a simple and valid method of categorising COPD severity (Bestall et al. 1999; Koulouris et al. 2003). The PSFS asks participants to list the five important activities that they are unable to do, or have difficulty undertaking, and rate their ability to perform the activities on a scale of zero ('unable to perform activity') to 10 ('able to perform activity at same level as before this problem'). This format is highly specific for each participant and has been shown to be reliable and valid (Stratford et al. 1995). The Maintenance Program Assessment also obtained demographic data 
including: age; gender; current disease symptoms; smoking history; activity of daily living functional profile; self management techniques; and current support.

\section{Quality of life}

Quality of life was measured in terms of health status by the SF-36 Health Survey and the St-George’s Respiratory Questionnaire. The SF-36 Health Survey measures eight domains of health: physical functioning; role limitations due to physical health; bodily pain; general health perceptions; vitality; social functioning; role limitations due to emotional problems; and mental health. It has been tested and validated extensively, being reported to have high internal consistency with Cronbach's alpha between 0.8 0.85 (Brazier et al. 1992; Garratt et al. 1993; Lyons, Perry \& Littlepage 1994).

The St-George’s Respiratory Questionnaire (SGRQ) is a 50 item self-administered survey widely used for individuals with asthma or COPD (Jones et al. 1992; Ketelaars et al. 1997; Spencer et al. 2001; Ferrer et al. 2002). It has been shown to be a diseasespecific valid instrument measuring the impact on overall health, daily life, and perceived well-being (Jones et al. 1992; Meecham-Jones et al. 1995; Jones \& Bosh 1997; Jones 2001). Internal consistency for this scale has been reported as high, with the 'Symptoms', 'Activity' and 'Impact' scales having a Cronbach's alpha $>0.7$ and the 'Overall’ scale having a Cronbach’s alpha >0.9 (Ferrer et al. 2002).

In addition to these measures, the Community Respiratory Nurse Educator and Physiotherapist working with the participants recorded qualitative, contextual data about the participant in their client files. This included providing commentary on 
issues such as: hospitalization; death of spouse; house relocation; and general anecdotal comments from the participant about how they were feeling.

\section{Data Analysis}

The Statistical Package for the Social Sciences (SPSS Inc., Chicago, IL, USA), Versions 12.0 and 13.0 and the Statistical Analysis System (SAS Institute Inc, Cary, NC, USA), Version for Windows 9.1 (SAS Institute Inc, 2001) were used to analyse the data. Analysis was conducted on all data that was collected and available for all three time points. Data are described as percentages, means (SD) or medians (IQR) where data was not normally distributed. Comparison of scores at pre-intervention, six months and post-intervention were undertaken for all measures, with the exception of the COPD Self-Efficacy Scale where comparisons were made only between pre and post-intervention. Due to the small number of complete data sets, non-parametric repeated measures, Wilcoxon Signed Rank test and Friedman tests, were undertaken on scores from the St George's Respiratory Questionnaire (SGRQ) and the COPD Self-Efficacy Scale.

To investigate whether there was a relationship between self-efficacy and the effects of the maintenance program in COPD individuals, a series of Pearson's productmoment correlations were undertaken. Due to the limited completion of the 12 month outcome measures, correlations between changes in self-efficacy and changes in the functional (six-minute walk) and quality of life scores (SF-36 Health Survey and St George’s Respiratory Questionnaire) were not conducted. However, a correlational test was performed to analyse the relationship between the initial self-efficacy scores and the initial functional (six-minute walk; MRC Dyspnoea Scale; Patient Specific 
Functional Scale) and quality of life scores (SF-36 Health Survey and St George's Respiratory Questionnaire). A Mann-Whitney $U$ test and chi-square test were conducted to analyse significant differences between the participants who attended either the 12 month or six-month assessment and those who did not complete either assessment.

\section{RESULTS}

\section{Sample}

A total of 29 participants from the 58 individuals completing one of the referral hospitals' pulmonary rehabilitation programs were enrolled into the home-based maintenance program. All 29 participants agreed to take part in the research and Table 1 shows demographic and baseline statistics for these individuals. Numbers of participants who completed the outcome assessments and loss to follow up are described in Figure 1. As eight participants did not continue the program beyond a period of five months ( 0 - 5 months), they have been excluded from the outcome analysis. This is essentially due to limited outcome data but also considers that sustained benefit would be difficult to attribute to the PM program given the shorter length of time since completion of the PR program (1 - 6 months). No significant differences ( $>00.01$ ) were found on clinical or demographic variables between the group that continued the program for at least six months $(n=21)$ and the group that completed 5 months or less of the program $(n=8)$. [Insert Figure 1 and Table 1 here]

Reasons for discontinuation of the PM program or incomplete assessment are recorded in Table 2 and clearly show that the chronicity of the illness is the major explanation for missed data. Data from 21 participants has been included in the analysis. The literature identifies that benefits of pulmonary rehabilitation programs 
most often dissipate from between six to 12 months if strategies are not put in place. Therefore those who completed six months or more of the PM program and completed the six month assessment $(n=7)$ have been included in the analysis with participants who completed the program and 12 month measures $(n=14)$ (see Figure 1). Data are presented in Table 3 and separated by assessment interval (12 months and 6 months). [Insert Table 2 here]

\section{Respiratory function}

Respiratory function was tested using the MRC Dyspnoea scale and Patient Specific Functional Scale (PSFS). For the PSFS, 19/21 participants completed at least one post-assessment. Most of the participants (17/19) either maintained their functional level or showed a clinically significant improvement (a difference of greater than 0.9 from baseline) at the six month or 12 month interval. Two participants showed a clinically significant decline in the PSFS test at 12 months. The results from the MRC scale are less favourable. Although most participants (14/21) either maintained their grade or improved, 7 participants showed a decline. It is also important to note that two participants who remained unchanged in their MRC Dyspnoea grade were rated at Grade 5 at baseline indicating the most severe dyspnoea score and one which could not be 'worsened'.

\section{Functional exercise capacity}

Functional exercise capacity was examined using the six-minute walk test. Eighteen participants (18/21) completed a baseline and at least one post-intervention six-minute walk test. Two participants were unable to complete the walk due to ill-health while one participant declined attending the assessment. Of those participants taking the 
test, 15 showed no clinically significant difference while three showed a clinically significant decline (a difference of greater than 70 metres from baseline).

\section{Quality of life}

Analysis of participant scores for those who completed a baseline and $6 \mathrm{~m}$ or $12 \mathrm{~m}$ SGRQ (19/21) revealed no significant change in mean scale scores across the time interval. The mean differences are recorded in Table 3. The generic quality of life tool, the SF-36 Health Survey was poorly completed and therefore analysis was limited to a description of responses to the Reported Health Transition question (Q2). In this question respondents are asked: “Compared to one year ago, how would you rate your health in general now?” This question was answered by 20/21 participants. Sixteen participants rated their health as the same $(n=9)$ or improved $(N=7)$, while 4 participants reported that they were somewhat worse now. These findings and the absence of a significant decline in SGRQ scales is reflected in the anecdotal, qualitative data collected by the Community Respiratory Nurse Educator and Physiotherapist working with the participants. One participant stated that he/she 'had more good days than bad days' and that his/her 'mental attitude was a lot better', with improvements in his/her perceived quality of life. Another participant went as far as to state that he/she was feeling the best he/she had felt in 10 years. [Insert Table 3 here]

\section{Self-efficacy}

Self-efficacy was determined using the COPD Self-Efficacy scale at baseline and 12 months. Twelve participants (12/14) who completed the 12 month PM program also completed the Self-Efficacy scale. No statistically significant changes were revealed across the time interval (see Table 4). A correlational test was performed to explore 
the relationship between the initial self-efficacy scores and the initial functional (sixminute walk; MRC Dyspnoea Scale; Patient Specific Functional Scale) and quality of life scores (St George’s Respiratory Questionnaire). A significant, positive correlation of moderate to high magnitude in the MRC Dyspnoea scale and the total SGRQ and sub-scales scores was observed (see Table 5). These correlations indicate that higher self-efficacy was associated with greater severity of COPD and better health-related quality of life (see Table 5). [Insert Table 4 and Table 5 here]

\section{Program attendance}

Overall, there were no significant differences found between the participants who attended the final 12 month program session and those that did not attend the final 12 month session according to: age; gender; diagnosis type; baseline severity; years since diagnosis; and initial self-efficacy scores.

\section{DISCUSSION}

The incidence of COPD is high, being the third leading cause of "burden of disease" and the fourth highest cause of death in men in Australia (AIHW 2000). The ageing population will see the prevalence continue and possibly increase, with the cost to the Australian community estimated at around \$800-900 million annually (McKenzie et al. 2003). In addressing this, a number of rehabilitation programs have been established for individuals with COPD. The literature has shown these to be extremely effective in their outcomes, although Foglio, Ambrosino \& Agati (2007) identifies that benefits most often dissipate from between six to 12 months if the strategies put in place are not maintained. To compound the situation further, relatively little is known about effective maintenance strategies (Lacasse et al. 2001, p. 5). In light of this, the study provides preliminary data on the effects of such a program on 
individuals with COPD and conveys some of the difficulties in measuring the effectiveness of a long program (12 months) with participants who have chronic ill health. As such, it provides important information to aid investigators planning the design of similar research with this population.

Data analysis showed that for most participants functional level was maintained or there were clinically significant improvements in: participants' respiratory functioning; functional exercise capacity; self-efficacy; and, reported health transition scores in quality of life (SF-36 Q.2), where it was reported that health was either the same or somewhat better than a year ago. The MRC Dyspnoea ratings were least convincing, with 42.9 percent of participants revealing a higher and therefore worse grading at the six month or 12 month-assessment. An interesting finding revealed an association between higher self-efficacy and worse functional status and better healthrelated quality of life (SGRQ scale scores) at baseline. Thus, participants with high dyspnoea severity had increased self-efficacy levels, suggesting that clients who have worse functional status may have a vested interest in trusting their ability to improve their condition in line with the 'Perceived Severity' construct of The Health Belief Model (Champion \& Sugg Skinner, 2008). Furthermore higher self-efficacy was also linked to better quality of life, suggesting a possible factor in maintaining motivation during a 12 month maintenance program. These results and the consensus that the benefits of completing a PR program are likely to decline after six months suggest that the maintenance program in this study is likely to have contributed to the low dissipation levels post pulmonary rehabilitation in COPD individuals participating in the program. As the purpose of the program was to maintain participant gains in functional ability, fitness and ability to self-manage after completion of an eight-week 
pulmonary rehabilitation programs, it appears that the program facilitated clinically significant results, especially considering the number of participants who experienced an un-associated decline in health during the 12 month study period.

From a methodological perspective, this study was limited in its ability to reveal generalisable results. The pre-test post-test design was unable to detect statistically significant findings as the sample size was too small and this was compounded by a considerable loss to follow-up and limited adherence. It is important to note that the intervention was designed to maintain benefits and therefore an increase in functioning was not expected, however statistically significant declines would be valuable to detect. Furthermore the study design did not include a control group, making it difficult to attribute the findings to the intervention. The inclusion of a control group to this study was in many ways impracticable. There was no 'usual' or 'standardised' care following the PR program, therefore it would have been difficult to maintain clients' motivation during a 12 month period of 'no care'. Importantly anecdotal evidence suggested that clients participating in the PM program from 2003 - 2005 were highly satisfied with the program and were maintaining functional abilities. For this reason it was considered unreasonable to preclude COPD patients, many with moderate to severe respiratory problems, from the PM program. And finally, self-selection is often necessary when participating in programs that necessitate a willingness and motivation to follow the program guidelines and health professional recommendations. Randomising people to the intervention would have required a significant length of time to meet the sample size requirements and therefore would have been beyond the scope of this small study. 
Clearly, overcoming problems with recruitment and adherence are primary considerations when researching effectiveness of maintenance programs. Incorporating qualitative methods is likely to overcome some limitations to small data sets by contributing more detail to the findings. However, it should also be recognised that when conducting any maintenance program research a level of unpredictability in terms of participant attrition/loss may be expected given the chronicity of COPD and the negative impact it has on individuals. No maintenance program can stop COPD from continuing to worsen in time. There are many factors likely to play a role in continuation of the PM program and adherence to the program guidelines. Unfortunately, due to incomplete data and a small sample size, the COPD self-efficacy scale was limited in its ability to detect an association between selfefficacy and program adherence and continuation. Factors which influence adherence and continuation should be investigated in future studies.

\section{Limitations and Recommendations}

Inconsistent collection of data due to participant loss (i.e. ill-health, death, lack of commitment etc) at pre, six months and post-intervention (12 months) resulted in incomplete data sets and a high level of missing information, although, it should be noted that the sample size for this study is similar to that observed in previous research (Romagnoli et al. 2006; Puente-Maestu et al. 2003; Grosbois et al. 1999; Wijkstra et al. 1996). This made the sample size difficult to analyse and from which to infer statistically significant findings. Future studies require larger sample sizes and attention to recruitment and adherence of participants to complete the program. A post hoc power analysis based on this study's finding was undertaken to identify what the appropriate sample size would be for future research. Data from the SGRQ, a disease- 
specific QOL tool and primary endpoint was used. The mean difference between baseline and 12-month Total SGRQ scores and standard deviation (as reported in Table 3) revealed an effect size (Cohens $d$ ) of -0.0801754 . Using this effect size, GPower post hoc calculations showed, that a future study would require $n=100$ to obtain a power $=0.800$, with a $\alpha$ of 0.05 , using a matched pairs analysis framework.

We recommend that mainteance program measures to assess participant outcomes should ideally involve fewer measures, easily administered and focus more on specific elements, such as quality of life or respiratory function. This will build a solid, reliable evidence-base for maintenance programs and their specific benefits and outcomes.

\section{CONCLUSION}

These results are equivocal and are limited to this particular sample. Nevertheless this pilot study indicates that a maintenance program may produce positive benefits for those COPD individuals who adhere to the program and it highlights the importance of encouraging participant motivation and adherence to the program when conducting maintenance research. Further research into the effects of maintenance programs for people with COPD is needed to help establish a broader evidence-base and further understanding of the specific outcomes. Future studies should explore the effects of a pulmonary maintance program in a larger sample and use the results from this research to promote the health benefits of being involved in such a program to potential participants.

\section{IMPLICATIONS FOR PRACTICE}

The outcomes of the research provide evidence for improving patient care through the use of a community based strategy. Improving the exercise capacity and ability to do 
daily activities for patients with COPD through home-based strategies may have financial benefits in terms of reduced hospital admissions, reduced psychological stress, and improved quality of life and needs further investigation. This also has the potential to improve quality of life for family caregivers of these patients. The principles of a model of care that involves self regulation and monitoring also has the potential to be tailored for use in other health care settings and for other chronic disease processes. Thus, the outcomes of this research have the potential to lead to research in other health care areas. This research also adds to the knowledge on what strategies may contribute to the maintenance of benefits of pulmomany rehabilitation.

\section{ACKNOWLEDGEMENTS}

The authors wish to acknowledge the support and encouragement received from the respiratory team and management of the Brisbane South Respiratory Service, in particular Noel Pamplin, CN. This study was funded by Griffith University Research Centre for Clinical and Community Practice Innovation. 


\section{References}

American Thoracic Society (2002) ATS Statement: Guidelines for the Six-Minute Walk Test, American Journal of Respiratory and Critical Care Medicine 166, 111117.

Australian Institute of Health and Welfare (2000) The burden of disease and injury. Australia's Health 2000. AIHW, Canberra.

Australia Institute of Health and Welfare (2004) National morbidity database. Australia's Health 2004. AIHW, Canberra.

Bestall J, Paul E, Garrod R, Garnham R, Jones P and Wedzicha J (1999) Usefulness of the Medical Research Council (MRC) Dyspnoea scale as a measure of disability in patients with chronic obstructive pulmonary disease, Thorax 54, 581-586.

Brazier J, Harper R, Jones N, O’Cathain A, Thomas K, Usherwood T and Westlake L (1992) Validating the SF-36 health survey questionnaire: new outcome measure for primary care, British Medical Journal 305, 160-164.

Celli B (1995) Pulmonary rehabilitation in patients with COPD, American Journal of Respiratory and Critical Care Medicine 152, 861-864.

Champion V and Sugg Skinner C (2008) The Health Belief Model, In K Glanz, B Rimer and K Viswanath, $4^{\text {th }}$ ed. Health Behavior and Health Education: theory, research, and practice. San Francisco: Jossey-Bass 
Cockram J, Cecins N, and Jenkins S (2006) Maintaining exercise capacity and quality of life following pulmonary rehabilitation, Respirology 11(1), 98-104.

Covey M, Larson J, Wirtz S, Berry J, Pogue N, Alex C and Patel M (2001) Highintensity inspiratory muscle training in patients with chronic obstructive pulmonary disease and severely reduced function, Journal of Cardiopulmonary Rehabilitation 21, 231-240.

European Respiratory Society: European Lung White Book (2003) Huddersfield, European Respiratory Society Journals Ltd.

Ferrer M., Villasante C, Alonso J, Sobradillo V, Gabriel R., Vialgut G, Masa J, Viejo J, Jimenez-Ruiz C and Miravitlles M (2002) Interpretation of quality of life scores from the St George's Respiratory Questionnaire, European Respiratory Journal 19, 405-413.

Foglio K, Ambrosino N, and Agati S (2007). Maintaining the benefits of pulmonary rehabilitation for patients with chronic obstructive pulmonary disease: where are we now? Chron Respir Dis 4(3), 131-133.

Garratt A M, Ruta D A, Abdalla M I, Buckingham J K and Russell I T (1993) The SF36 health survey questionnaire: an outcome measure suitable for use in the NHS? British Medical Journal 306, 1440-1444. 
Global Initiative for Chronic Obstructive Lung Disease (2007) Global Strategy for the Diagnosis, Management, and Prevention of Chronic Obstructive Pulmonary Disease: Updated 2007. 2006 Medical Communications Resources Inc.

Griffiths T, Burr M, Campbell I, Lewis-Jenkins V, Mullins J, Shiels K, Turner-Lawlor P, Payne N, Newcombe R, Lonexcu A, Thomas J and Tunbridge J (2000) Results at 1 year of outpatient multidisciplinary pulmonary rehabilitation: a randomised controlled trial, Lancet 355, 362-368.

Grosbois J M, Lamblin C, Lemaire B Chekroud H, Dernis J M, Douay B and Fortin F (1999) Long-terms benefits of exercise maintenance after outpatient rehabilitation program in patients with chronic obstructive pulmonary disease, Journal of Cardiopulomonary Rehabilitation 19, 216-225.

Jones, P. (2001). Health status measurement in chronic obstructive pulmonary disease, Thorax 56, 880-887.

Jones P and Bosh T (1997). Quality of life changes in COPD patients treated with salmeterol, American Journal of Respiratory and Critical Care Medicine 155, 12831289.

Jones P, Quirk R, Baveystock C and Littlejohns P (1992) A self-complete measure of health stuatus for chronic airflow limitation: The St. George's Respiratory Questionnaire, American Review of Respiratory Disease 145(6), 1321-1327. 
Kara M and Asti T (2004) Effect of education on self-efficacy of Turkish patients with chronic obstructive pulmonory disease, Patient Education and Counseling 55, 114-120.

Ketelaars C, Abu-Saad H, Scholsser M, Mostert R and Wouters E (1997) Long-term outcome of pulmonary rehabilitation in patients with COPD, Chest 112, 363-369.

Koulouris N, Retsou S, Kosmas E, Dimakou K, Malagari K, Mantzikopoulos G, Koutsoukou A, Milic-Emil J and Jordanoglou J (2003) Tidal expiratory flow limitation, dyspnoes and exercise capacity in patients with bilateral bronchiectasis, European Respiratory Journal 21, 743-748.

Lacasse Y, Brosseau L, Milne S, Martin S, Wong E, Guyatt G H, Goldstein R S and White J (2001) Pulmonary rehabilitation for chronic obstructive pulmonary disease, The Cochrane Database of Systematic Review 4.

Lyons R A, Perry H M, Littlepage B N C (1994) Evidence for the validity of the short form 36 questionnaire (SF-36) in the elderly population, Age and Ageing 23, 182-184. McKenzie D K, Frith P A, Burdon J G W and Town G I (2003) The COPDX Plan: Australian and New Zealand Guidelines for the management of Chronic Obstructive Pulmonary Disease, Medical Journal of Australia 178 (6 Suppl 17 Mar), S1-S40. 
Man W, Polkey M, Donaldson N, Gray B, and Moxham J (2004) Community pulmonary rehabilitation after hospitalisation for acute exacerbations of chronic obstructive pulmonary disease: randomised controlled study, BMJ 329(7476), 12091213.

McKenzie D K, Frith P A, Burdon J G W, \& Town G I (2003) The COPDX Plan: Australian and New Zealand Guidelines for the management of chronic obstructive pulmonary disease. Medical Journal of Australia, 178 (6 Suppl.), S1-S40.

Meecham Jones D J, Paul E A, Jones P W Wedzicha J A (1995) Nasal pressure support ventilation plus oxygen compared with oxygen therapy alone in hypercapnic COPD, American Journal of Respiratory Critical Care Medicine 152, 538-544.

National Center for Health Statistics. National Vital Statistics System. Hyattsville, Maryland: U.S. Depatment of Health and Human Services, CDC, NCHS, 1995-2000.

National Heart, Lung, and Blood Institute. Morbidity and Mortality: 2002 Chartbook on Cardiovascular, Lung, and Blood Diseases. Bethesda, Maryland: U.S. Department of Health and Human Services, NIH, NHLBI. May 2002.

Oh $\mathrm{H}$ and Seo W (2006) Meta-analysis of the effects of respiratory rehabilitation programmes on exercise capacity in accordance with programme characteristics, Journal of Clinical Nursing 16, 3-15. 
Puente-Maestu L, Luisa Sanz M, Sanz P, Ruiz de Ona J M, Arnedillo A and Casaburi R (2003) Long-term effects of a maintenance program after supervised or selfmonitored training programs in patients with COPD, Lung 181, 67-78.

Romagnoli M, Dell’Orso D, Lorenzi C, Crisafulli E, Costi S, Lugli D and Clini E M (2006) Repeated Pulmonary Rehabilitation in Severe and Disabled COPD Patients, Respiration 73, 769-776.

Sciurba F, Criner G, Lee S, Mohsenifar Z, Shade D, Slivka W and Wise R (2003) SixMinute Walk Distance in Chronic Obstructive Pulmonary Disease, American Journal of Respiratory and Critical Care Medicine 167, 1522-1527.

Spencer S, Calverley P, Burge S and Jones P (2001) Health status deterioration in patients with Chronic Obstructive Pulmonary Disease, American Journal of Respiratory and Critical Care Medicine 163(1), 122 - 128.

Stratford P, Gill C, Westaway M and Binkley J (1995) Assessing disability and change on individual patients: a report of patient specific measure, Physiotherapy Canada 47(4), 258-263.

Wigal J K, Creer T L and Kotses H (1991) The COPD Self-Efficacy Scale, Chest 99(5), 1193-6. 
Wijkstra P J, van Altena R, Kraan J, Otten V, Postma D S and Koeter G H (1994) Quality of life in patients with chronic obstructive pulmonary disease improves after rehabilitation at home, European Respiratory Journal 7, 269-273.

Wijkstra P J, van der Mark T W, Kraan J, van Altena R, Koeter G H and Postma D S (1996) Long-term effects of home rehabilitation on physical performance in chronic obstructive pulmonary disease, American Journal of Critical Care Medicine 153, 1234-1241.

World Health Organization (2000) The World Health Report 2000: Health systems: Improving performance. Geneva, Switzerland. 


\section{Tables}

Table 1: Sample Characteristics

\begin{tabular}{|c|c|c|}
\hline \multicolumn{3}{|l|}{ Variables $(\mathrm{n}=29)$} \\
\hline Gender & Male (N (\%) & $18(62.1)$ \\
\hline Age & $\begin{array}{l}\text { Mean (SD) } \\
\text { Min - Max }\end{array}$ & $\begin{array}{l}71.7(8.45) \\
(50-85)\end{array}$ \\
\hline Years since diagnosis & Median (IQR) & $6.0(2-14)$ \\
\hline FEV1 $(n=24)$ & Median (IQR) & $41 \%(30 \%-56 \%)$ \\
\hline Level of condition $(n=28)$ & $\begin{array}{l}\text { Mild (N (\%) } \\
\text { Moderate (N (\%) } \\
\text { Severe (N (\%) }\end{array}$ & $\begin{array}{l}2(6.9) \\
13(44.8) \\
13(44.8)\end{array}$ \\
\hline Supplemental oxygen use $(\mathrm{n}=27)$ & No (N (\%) & $23(85.2)$ \\
\hline $\begin{array}{l}\text { Current smoker }(\mathrm{n}=28) \\
\text { Former smoker }(\mathrm{n}=23)\end{array}$ & $\begin{array}{l}\text { No (N (\%) } \\
\text { Yes (N (\%) }\end{array}$ & $\begin{array}{l}23(82.2) \\
19(82.6)\end{array}$ \\
\hline $\mathrm{BMI}(\mathrm{n}=27)$ & Median (IQR) & $25.0(22.3-30.3)$ \\
\hline Assistance with ADLs $(\mathrm{n}=28)$ & No (N (\%) & $26(92.9)$ \\
\hline Assistance with IADLs $(\mathrm{n}=27)$ & No (N (\%) & $17(63.0)$ \\
\hline $\begin{array}{l}\text { Use of self-management techniques } \\
(\mathrm{n}=27)\end{array}$ & Yes (N (\%) & $20(74.1)$ \\
\hline Family support/care $(\mathrm{n}=27)$ & Yes (N (\%) & $18(66.7)$ \\
\hline
\end{tabular}


Table 2: Reasons for discontinuation of program or incomplete assessment

\begin{tabular}{lcc}
\hline Reasons & $\begin{array}{c}\text { Continued program } \\
<6 \mathrm{~m}(\mathrm{n}=8)\end{array}$ & $\begin{array}{c}\text { Continued program } \\
>6 \mathrm{~m} \text {, but only one } \\
\text { post-assessment }(\mathrm{n}=7)\end{array}$ \\
\hline Ill health & 3 & 2 \\
\hline Death & 1 & 1 \\
\hline Moved & 1 & 2 \\
\hline Declined/Unable & 1 & 1 \\
\hline Unable to contact & 1 & \\
\hline Not known & 1 & 1 \\
\hline
\end{tabular}


Table 3: Outcomes

\begin{tabular}{|c|c|c|c|}
\hline & & $12 \mathrm{~m}(\mathrm{n}=14)$ & $6 \mathrm{~m}$ only $(\mathrm{n}=7)$ \\
\hline \multirow{2}{*}{ Age } & Mean (SD) & $72.9(8.37)$ & $67.3(11.41)$ \\
\hline & Min - Max & $54-85$ & $50-81$ \\
\hline \multirow{3}{*}{ Level of condition } & Mild (N\%) & $1(7.1)$ & 0 \\
\hline & Moderate (N\%) & $6(42.9)$ & $5(71.4)$ \\
\hline & Severe (N\%) & $7(50.0)$ & $2(28.6)$ \\
\hline \multirow{3}{*}{$\begin{array}{l}\text { Patient Specific } \\
\text { Functional Scale }\end{array}$} & CS decline (N\%) & $1(8.3)^{n=12}$ & $1(14.3)$ \\
\hline & No CS difference (N\%) & $7(58.3)^{\mathrm{n}=12}$ & $4(57.1)$ \\
\hline & CS improvement (N\%) & $4(33.3)^{n=12}$ & $2(28.6)$ \\
\hline \multirow{3}{*}{ MRC Dyspnoea Scale } & Worse (N\%) & $5(35.7)$ & $2(28.6)$ \\
\hline & Same (N\%) & $7(50.0)$ & $4(57.1)^{\#}$ \\
\hline & Better (N\%) & $2(14.3)$ & $1(14.3)$ \\
\hline \multirow{3}{*}{$\begin{array}{l}\text { St George Respiratory } \\
\text { Questionnaire Scales }\end{array}$} & Symptoms (Mean Diff, SD)* & $\underset{n=12}{-0.019,12.83}$ & $\begin{array}{l}-7.113,11.56 \\
\mathrm{n}=4\end{array}$ \\
\hline & Activity (Mean Diff SD)* & $\begin{array}{l}-3.392,17.08 \\
\mathrm{n}=12\end{array}$ & $\underset{n=5}{1.904,13.24}$ \\
\hline & Impact (Mean Diff SD)* & $\begin{array}{l}-0.061,18.21 \\
\mathrm{n}=12\end{array}$ & $\underset{\mathrm{n}=4}{4.318,5.17}$ \\
\hline \multirow{5}{*}{$\begin{array}{l}\text { Compared to one year } \\
\text { ago how would you rate } \\
\text { your general health now? }\end{array}$} & $\begin{array}{l}\text { Much worse now than one } \\
\text { year ago (N\%) }\end{array}$ & 0 & 0 \\
\hline & $\begin{array}{l}\text { Somewhat worse now than } \\
\text { one year ago (N\%) }\end{array}$ & $2(14.3)$ & $2(33.3)^{\mathrm{n}=6}$ \\
\hline & $\begin{array}{l}\text { About the same as one year } \\
\text { ago (N\%) }\end{array}$ & $7(50.0)$ & $2(33.3)^{\mathrm{n}=6}$ \\
\hline & $\begin{array}{l}\text { Somewhat better now than one } \\
\text { year ago (N\%) }\end{array}$ & $5(35.7)$ & $1(16.7)^{\mathrm{n}=6}$ \\
\hline & $\begin{array}{l}\text { Much better now than one year } \\
\text { ago (N\%) }\end{array}$ & 0 & $1(16.7)^{\mathrm{n}=6}$ \\
\hline
\end{tabular}


Table 4: COPD Self - Efficacy Scale: Wilcoxon Signed Rank Test

\begin{tabular}{lcccc}
\hline \multicolumn{1}{c}{$\begin{array}{c}\text { COPD Self-Efficacy } \\
\text { Scale (n=14) }\end{array}$} & $\begin{array}{c}\text { Initial Mean } \\
\text { Score }\end{array}$ & $\begin{array}{c}\text { 12 Month } \\
\text { Mean Score }\end{array}$ & Z & $p=$ \\
\hline Negative Affect & 1.27 & 1.55 & -0.524 & 0.600 \\
\hline Intense emotional & 1.38 & 1.63 & -0.771 & 0.441 \\
\hline Physical Exertion & 2.00 & 1.80 & -0.351 & 0.725 \\
\hline Weather/Environment & 2.00 & 2.00 & -0.223 & 0.824 \\
\hline $\begin{array}{l}\text { Behavioural Risk } \\
\text { Factors }\end{array}$ & 1.50 & 1.67 & -0.948 & 0.343 \\
\hline $\begin{array}{l}\text { Total Self-Efficacy } \\
\text { Score }\end{array}$ & 2.87 & 3.09 & -1.120 & 0.263 \\
\hline
\end{tabular}

Notes to table: Mean scoring: 1 =' Very Confident'; 2 = 'Pretty Confident'; 3 = 'Somewhat Confident'; 4 = 'Not very Confident'; 5 ='Not at all Confident'.

Table 5: Pearson's Product Moment Correlation of the initial total COPD Self-Efficacy score and initial MRC Dyspnoea grade and initial StGeorge's Respiratory Questionnaire (SGRQ) scale scores

\begin{tabular}{|c|c|c|c|c|c|}
\hline & $\begin{array}{c}\text { Initial } \\
\text { Mean } \\
\text { MRC } \\
\text { Dyspnoea } \\
\text { Scale } \\
\end{array}$ & $\begin{array}{c}\text { Initial } \\
\text { Mean } \\
\text { SGRQ } \\
\text { Symptom } \\
\text { Score } \\
\end{array}$ & $\begin{array}{c}\text { Initial } \\
\text { Mean } \\
\text { SGRQ } \\
\text { Activity } \\
\text { Score }\end{array}$ & $\begin{array}{c}\text { Initial } \\
\text { Mean } \\
\text { SGRQ } \\
\text { Impacts } \\
\text { Score } \\
\end{array}$ & $\begin{array}{c}\text { Initial } \\
\text { Mean } \\
\text { SGRQ } \\
\text { Total } \\
\text { Score } \\
\end{array}$ \\
\hline Pearson correlation & 0.680 & 0.678 & 0.606 & 0.892 & 0.930 \\
\hline $\begin{array}{c}\text { Sig. } \\
\text { (2-tailed) }\end{array}$ & 0.044 & 0.094 & 0.149 & 0.007 & 0.002 \\
\hline $\mathrm{N}$ & 9 & 7 & 7 & 7 & 7 \\
\hline
\end{tabular}




\section{Figures}

Figure 1: Patient enrolment into Pulmonary Maintenance Program and participant response and loss to follow-up

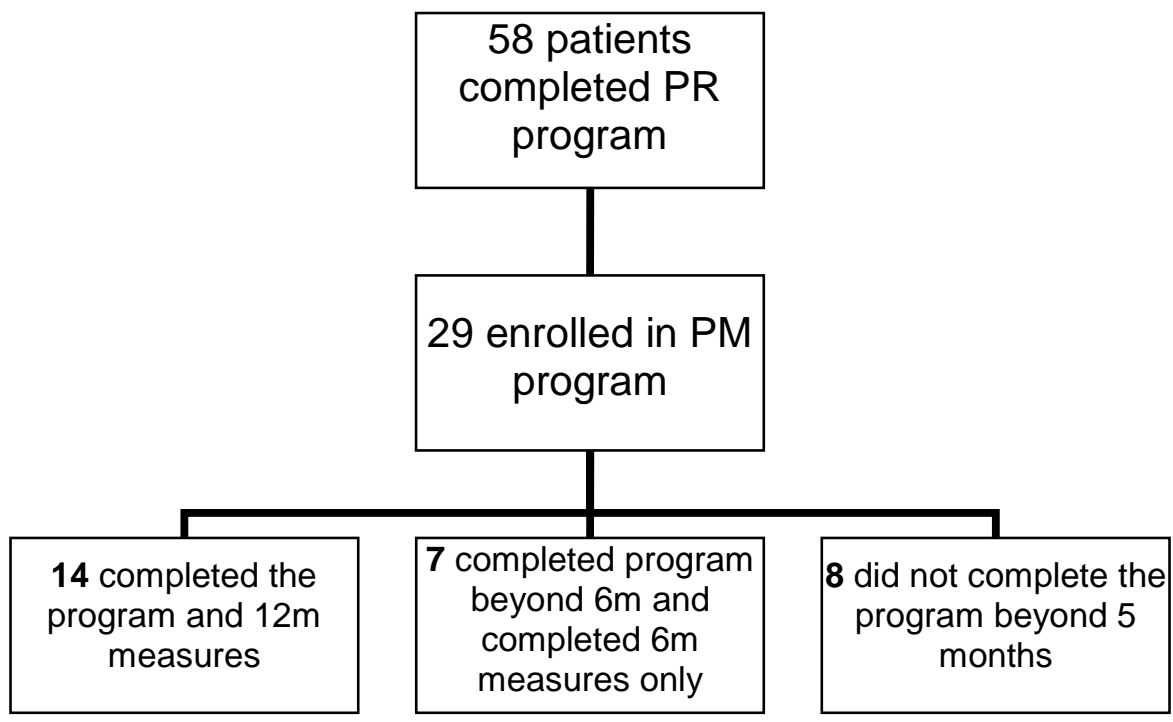

